\title{
The Very First Changes in the Tongue with the Development of Cancer
}

\author{
Kenta Hamada, Ryu Ishihara, Yasushi Yamasaki \\ Department of Gastrointestinal Oncology, Osaka Medical Center for Cancer and Cardiovascular Diseases, Osaka, Japan
}

\section{Doi: 10.12890/2017_000577 - European Journal of Case Reports in Internal Medicine - @ EFIM 2017}

Received: $18 / 01 / 2017$

Accepted: 20/01/2017

Published: 08/02/2017

How to cite this article: Hamada K, Ishihara R, Yamasaki Y. The very first changes in the tongue with the development of cancer. EJCRIM 2017;4: doi:10.12890/2017_000577

Conflicts of Interests: The Authors declare that there are no competing interests.

This article is licensed under a Commons Attribution Non-Commercial 4.0 License

\section{ABSTRACT}

We describe the case of an elderly man with a 3-month history of pain at the tip of his tongue due to a lingual cancer. The lesion appeared slightly depressed and reddish. Our images show the very first changes in the tongue with the development of cancer. Patients with tongue pain often visit the internal medicine department first, so highlighting this case will help physicians detect lingual cancer quickly.

\section{LEARNING POINTS}

- Surgical treatment of lingual cancer may affect several tongue functions and remarkably decrease quality of life, so early detection is important to both improve prognosis and maintain quality of life after surgery.

- Lingual cancer first appears as a slightly depressed reddish lesion as lingual papillae disappear.

- Since patients with tongue pain often visit the internal medicine department first, early detection of lingual cancer depends on physicians.

\section{KEYWORDS}

Early lingual cancer; squamous cell carcinoma; tongue pain

\section{CASE REPORT}

A 79-year-old man presented with a 3-month history of pain at the tip of his tongue. Examination of the oral cavity revealed a 10 mm slightly depressed reddish lesion at the tip of his tongue (Fig. 1). Endoscopy showed the lesion more clearly (Fig. 2). Narrow-band imaging, one of the most popular endoscopic modalities with which to enhance the surface structure, showed disappearance of the lingual papillae in the depressed area (Fig. 3).No enlargement of the cervical lymph nodes was detectable. A biopsy was performed, and histopathological examination revealed squamous cell carcinoma. The tumour was surgically removed, and no reconstruction of the tongue was needed. The tongue pain resolved after surgery.

\section{DISCUSSION}

The tongue is important for speech, swallowing, mastication and oral hygiene ${ }^{[1]}$. Surgical treatment of lingual cancer may affect these functions and remarkably decrease quality of life ${ }^{[2]}$. Therefore, early detection of lingual cancer is important to both improve prognosis and maintain quality of life after surgery. However, early detection of lingual cancer is still difficult, primarily because most physicians are unfamiliar with its early findings although patients with tongue pain often visit the internal medicine department first. We hope our images, which show the very first changes in the tongue with the development of cancer, will help physicians recognize early lingual cancer. 


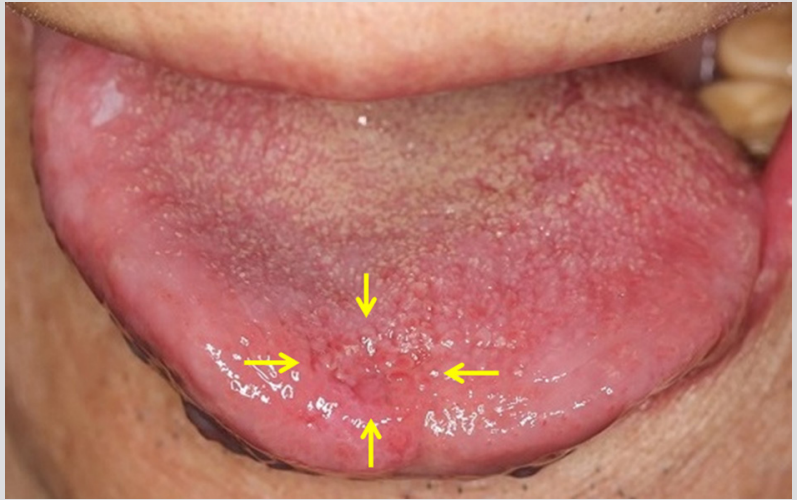

Figure 1. A $10 \mathrm{~mm}$ slightly depressed reddish lesion on the tip of our patient's tongue
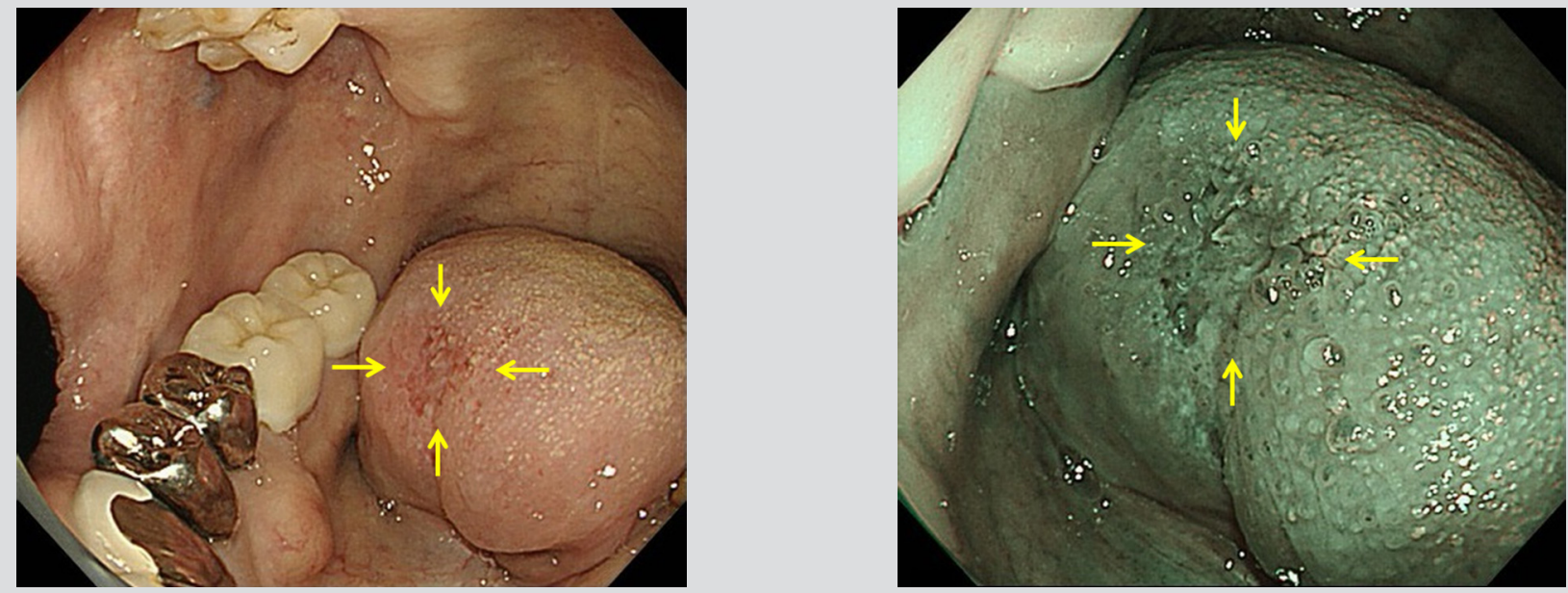

Figure 2. Endoscopic image showing the lingual lesion more clearly

Figure 3 Narrow-band imaging showing disappearance of the lingual papillae in the lesion

\section{REFERENCES}

1. Urken ML, Moscoso JF, Lawson W, Biller HF. A systematic approach to functional reconstruction of the oral cavity following partial and total glossectomy. Arch Otolaryngol Head Neck Surg 1994;120:589-601.

2. Jeong WH, Lee WJ, Roh TS, Lew DH, Yun IS. Long-term functional outcomes after total tongue reconstruction: consideration of flap types, volume, and functional results. Microsurgery 2015 Jun 29. doi: 10.1002/micr.22440. [Epub ahead of print] 